Journal of Animal and Veterinary Advances 9 (12): 1717-1719, 2010

ISSN: $1680-5593$

(C) Medwell Journals, 2010

\title{
The Effect of Spermatozoa Number on Fertility Rate of Chicken in Artificial Insemination Programs
}

\author{
S. Tabatabaei \\ Department of Animal Science, Faculty of Animal and Food Science, \\ Ramin (Khuzestan) Agricultural and Natural Resources University, \\ P.O. Box 63417-73637, Mollasani, Ahvaz, Iran
}

\begin{abstract}
The purpose of this study was to evaluate tshe optimum number of spermatozoa for highest fertility in Ross-308 broiler breeder chicken. About 24 Ross hens in 4 treatment groups were used. Semen was collected from 8 Ross roosters by abdominal massage and pooled in glass tube. After initially dilution with modified Ringer's solution and determination the spermatozoa concentration by hemocytometer, the semen was diluted further. About 50, 75, 100 and 150 million spermatozoa in $0.1 \mathrm{~mL}$ were inseminated to treatment groups for 4 weeks ( 4 times repeating). Eggs were collected daily from the 2nd day post insemination and incubated. After 7 days of incubation, the eggs were candled for fertility rate. In treatment groups that were inseminated with $50,75,100$ and 150 million spermatozoa, fertility rates were $52.85 \pm 4.15,72.37 \pm 5.28,87.64 \pm 4.81$ and $89.12 \pm 3.74 \%$, respectively. As shown to this results, fertility rate in treatment group that was inseminated with 50 million spermatozoa was lowest $(52.85 \pm 4.15 \%)$ and then increased significantly $(\mathrm{p}<0.05)$ with increasing the sperm number and reached to maximum in treatment group that was inseminated with 100 million spermatozoa $(87.64 \pm 4.81 \%)$. Difference of fertility rate between treatment groups that were inseminated with 100 and 150 million spermatozoa $(87.64 \pm 4.81$ and $89.12 \pm 3.74 \%$, respectively) was not significant ( $p>0.05)$. It is concluded that optimum dose of spermatozoa for artificial insemination in Ross-308 chicken was 100 million sperm.
\end{abstract}

Key words: Sperm, optimum concentration, artificial insemination, Ross-308, significantly, hemocytometer

\section{INTRODUCTION}

In artificial insemination, often the semen of all roosters was mixed together. Because of this pooling, roosters are often not evaluated individually for reproductive potential at the time of collection beyond visual assessment of ejaculate color and volume (Holsberger et al., 1998). Fertilizing ability of the semen can be made by concentration, motility, live-dead and morphological evaluations. There is a negative correlation between body weight and sperm concentration, motility and viability of sperm in poultry (Alkan et al., 2002). Breeder flocks found to have high fertility are also thought to have high hatchability of fertile eggs. This assumption is supported by research of McDaniel et al. (1981) and Mclntyre et al. (1986). Factors affecting fertility and therefore hatchability have been reviewed in literature (Lake, 1983; Mclntyre et al., 1986). In domestic fowl, sperm numbers, type of hens (broiler or layer types) and age may affect the fertility of eggs (Talebi et al., 2009). Satisfactory fertility was obtained with $0.01 \mathrm{~mL}$ semen (Bratte and Ibe, 1989) but higher doses have been recommended (Bratte and Ibe, 1989). Although, levels of semen dilution ranging from 1:1-1:5 have been advocated other study indicated that delusions of up to 1:10 could produce high fertility and hatchability provided the inseminated quantity contained at least $100 \times 10^{6}$ spermatozoa (Bratte and Ibe, 1989). The purpose of this study is to evaluation the optimum spermatozoa number for high hatchability rate in Ross-308 broiler breeder chickens.

\section{MATERIALS AND METHODS}

For this study, 24 Ross broiler breeder strain 308 hens with the same ages ( 28 weeks) were used. These hens were placed in 4 treatment groups randomly. Each group was contain 6 hens. For insemination of these hens, 8 Ross broiler breeder strain 308 roosters with the same ages ( 28 weeks) were used. Females were separated from males throughout the study. All hens and roosters were maintained in enclosed houses and were fed with their own standard breeder diet.

All males and females received $16 \mathrm{~h}$ light day ${ }^{-1}$ throughout the study. Before beginning of AI, the hens were separated from roosters for 1 month and after this time, eggs collected and incubated for several days to ensure that the females didn't have any fertile eggs. The roosters were trained to give semen 10 days before the collection began. Semen was collected by the abdominal 
massage method (Lake, 1983). After exciting of roosters with abdominal massage, the male organ became swell and protrude outwards and downwards and white semen seen in the central furrow of the organ. The semen was milked down by firm finger pressure either side of the vent into the collecting tube.

If the semen which should be white was discolored due to contamination by fecal material or blood, it was useless and was eliminated. Modified Ringer's solution (sodium chloride: $68 \mathrm{~g}$, potassium chloride: $17.33 \mathrm{~g}$, calcium chloride: $6.42 \mathrm{~g}$, magnesium sulphate: $2.5 \mathrm{~g}$, sodium bicarbonate: $24.5 \mathrm{~g}$, distilled water: $10,000 \mathrm{~mL}$ ) was used as a diluent of semen.

After initially dilution of pooled semen with modified Ringer's solution and determination the spermatozoa concentration by hemocytometer, the pooled semen was divided in 4 parts. Parts 1, 2, 3 and 4 were diluted further in ranges that each $0.1 \mathrm{~mL}$ of diluted semen (volume of each insemination) contains 50, 75, 100 and 150 million spermatozoa, respectively. These diluted semen with different concentrations were inseminated to treatment groups.

The semen collection, dilution for various spermatozoa concentration and insemination to hens in different treatment groups performed weekly for 4 weeks (4 times repeating). Eggs were collected daily from the 2 nd day post insemination and incubated. After 7 days of incubation, the eggs of different treatment groups were candled for fertility rate. Fertility rate were analyzed by ANOVA and Duncan test.

\section{RESULTS AND DISCUSSION}

Fertility rate of eggs with deferent number of inseminated spermatozoa in Ross broiler breeder chickens is shown in Table 1. In treatment groups that were inseminated with 50, 75, 100 and 150 million spermatozoa, fertility rates were $52.85 \pm 4.15,72.37 \pm 5.28,87.64 \pm 4.81$ and $89.12 \pm 3.74 \%$, respectively.

As shown to this results, fertility rate in treatment group that was inseminated with 50 million spermatozoa was lowest ( $52.85 \pm 4.15 \%)$ and then increased significantly ( $<<0.05$ ) with increasing the sperm number and reached to maximum in treatment group that was inseminated with 100 million spermatozoa $(87.64 \pm 4.81 \%)$. Difference of fertility rate between treatment groups that were inseminated with 100 and 150 million spermatozoa (87.64 \pm 4.81 and $89.12 \pm 3.74 \%$, respectively) was not significant $(\mathrm{p}>0.05)$.

In this study, fertility rate in eggs laid by hens that received the 50 million spermatozoa was lowest and then increased significantly with increasing the sperm number and reached to maximum in eggs laid by hens that was
Table 1: Fertility rate of eggs with different number of inseminated spermatozoa in chicken

\begin{tabular}{lc}
\hline Sperm number (million) & Fertility rate (\%) \\
\hline 50 & $52.85 \pm 4.15$ \\
100 & $72.37 \pm 5.28^{\mathrm{b}}$ \\
150 & $87.64 \pm 4.81^{\mathrm{c}}$ \\
200 & $89.12 \pm 3.74^{\mathrm{ac}}$ \\
\hline
\end{tabular}

Fertility rates with different superscripts differ significantly $(p<0.05)$

inseminated with 100 million spermatozoa. Difference of fertility rate between treatment groups that were inseminated with 100 and 150 million spermatozoa was not significant. In a study by Eslick and Mcdaniel (1992), the lowest fertility was observed in eggs laid by hens that received the lowest dose ( 25 million) of spermatozoa. Unlike to the results, Eslick and Mcdaniel (1992) reported that the maximum fertility of eggs was achieved with use of 200 million spermatozoa not 100 million spermatozoa. There is indication that fertility declined with increasing dilution that called dilution effect (Bratte and Ibe, 1989). A similar downward linear trend in fertility was observed in chickens (Bratte and Ibe, 1989). While only one spermatozoa units with the egg to form the zygote, many spermatozoa enter the vitelline membrane (Bratte and Ibe, 1989). Taneja and Gowe (1961) hypothesized that the action of additional spermatozoa entering the vitelline membrane may play a role in the early development of the embryo. In present study, maximum fertility was achieved with use of 100 million spermatozoa. This result agree with that of Brillard and McDaniel (1986).

\section{CONCLUSION}

It is concluded that the best dose of spermatozoa for achieve the highest fertility of eggs laid by hens in artificial insemination in Ross-308 chicken was 100 million sperm.

\section{REFERENCES}

Alkan, S., A. Baran, O.B. Ozdas and M. Evecen, 2002. Morphological defects in turkey semen. Turk. J. Vet. Anim. Sci., 26: 1087-1092.

Bratte, L. and S.N. Ibe, 1989. Optimal Insemination interval, semen dose and dilution for optimum fertility in chickens under humid tropical conditions. Anim. Reprod. Sci., 20: 179-185.

Brillard, J.P. and G.R. McDaniel, 1986. Influence of spermatozoa numbers and insemination frequency on fertility in dwarf broiler breeder hens. Poult. Sci., 65: $2330-2334$.

Eslick, M.L. and G.R. Mcdaniel, 1992. Interrelationships between fertility and hatchability of eggs from broiler breeder hens. J. Applied Poult. Res., 1: 156-159. 
Holsberger, D.R., A.M. Donghue, D.P. Froman and M.A. Ottinger, 1998. Assessment of ejaculate quality and sperm characteristics in turkeys: Sperm mobility phenotype is independent of time. Poult. Sci., 77: 1711-1717.

Lake, P.E., 1983. Factors affecting the fertility level in poultry with special reference to artificial insemination. World's Poult. Sci., 39: 106-117.

McDaniel, G.R., J. Brake and R.D. Bushlong, 1981. Factors affecting broiler breeder performance. 1. Relationship of daily feed intake level to reproductive performance of pullets. Poult. Sci., 60: $307-312$.
Mclntyre, D.R., V.L. Chrislensen and L.G. Bagley, 1986. Effect of sperm numbers per insemination following early or late initial inseminations in Turkeys. Poult. Sci., 65: 1400-1404.

Talebi, A.R., R.A. Batavani and S. Tabatabaei, 2009. Comparison of oviductal sperm age on fertility, hatchability and embryonic death rates in iranian indigenous and ross-308 broiler breeder chickens. J. Anim. Vet. Adv., 8: 85-89.

Taneja, G.C. and R.S. Gowe, 1961. The effect of dosage of undiluted semen on fertility in two breeds of fowl. Br. Poult. Sci., 2: 81-89. 